\title{
Dietary exposure of juvenile common sole (Solea solea L.) to polybrominated diphenyl ethers (PBDEs): Part 2. Formation, bioaccumulation and elimination of hydroxylated metabolites
}

\author{
C. Munschy ${ }^{a}{ }^{*}$, K. Héas-Moisan ${ }^{a}$, C. Tixier ${ }^{a}$, G. Pacepavicius ${ }^{b}$ and M. Alaee ${ }^{b}$
}

a Institut Français de Recherche pour l'Exploitation de la Mer (IFREMER), Laboratory of Biogeochemistry of Organic Contaminants, Rue de l'lle d'Yeu, BP 21105, 44311 Nantes, Cedex 3, France

${ }^{\mathrm{b}}$ Aquatic Ecosystem Protection Research Division, Environment Canada, Burlington, ON, Canada

\footnotetext{
* Corresponding author : C. Munschy, email address : cmunschy@ifremer.fr
}

\begin{abstract}
:
The uptake, elimination and transformation of six PBDE congeners (BDE-28, -47, -99, -100, -153, 209) were studied in juvenile common sole (Solea solea L.) exposed to spiked contaminated food over a three-month period, and then depurated over a five-month period. Methoxylated (MeO-) and hydroxylated (OH-) PBDEs were determined in fish plasma exposed to PBDEs and compared to those obtained in control fish. While all $\mathrm{MeO}$ - and some $\mathrm{OH}$ - congeners identified in fish plasma were found to originate from non-metabolic sources, several $\mathrm{OH}$ - congeners, i.e., $\mathrm{OH}$-tetraBDEs and $\mathrm{OH}$ pentaBDEs, were found to originate from fish metabolism. Among these, 4'-OH-BDE-49 was identified as a BDE-47 metabolite. Congener 4'-OH-BDE-101, identified here for the first time, may be the result of BDE-99 metabolic transformation. Our results unequivocally showed that PBDEs are metabolised in juvenile sole via the formation of $\mathrm{OH}$ - metabolites. However, this was not a major biotransformation route compared to biotransformation through debromination.
\end{abstract}

Juvenile sole exposed to artificially-contaminated food showed the ability to biotransform PBDEs into hydroxylated metabolites; these meta-bolites accumulated in fish.

Keywords: Marine flatfish; PBDEs; Bioaccumulation; Biotransformation; Hydroxylated metabolites 


\section{Introduction}

Polybrominated diphenyl ethers (PBDEs) are among the most widely-used brominated

flame retardants and their presence has now been shown worldwide in all environmental compartments, including the deep ocean (Hites, 2004; Law et al., 2006; Tanabe et al., 2008; Shaw and Kannan, 2009). These contaminants have been a source of scientific concern for the last 10 years due to their persistence, bioaccumulation potential and toxicity to wildlife and humans (Darnerud et al., 2001; de Wit, 2002; Law et al., 2003; Legler, 2008; Ross et al., 2009).

Hydroxylated (OH-) and methoxylated (MeO-) PBDEs have also been the focus of several studies for approximately the last 15 years. However, data on their occurrence, fate and origins is scarce, especially in regard to marine biota. OH-PBDEs are now of particular interest, as their various toxic effects can be more potent than those of their non-hydroxylated parent congeners (Hamers et al., 2008). OH-PBDE effects on thyroid hormone homeostasis have already been reported (Brouwer et al., 1998; Meerts et al., $2000 ; 2001)$ resulting from their similarity to thyroxine (T4). These compounds can also act on oestradiol synthesis, elicit neurotoxic effects, and inhibit aromatase activity: most of these effects having been studied in mammal cells, including human cells (Meerts et al., 2001; Shaw and Kannan, 2009; Wan et al., 2009).

The industrial production or use of $\mathrm{MeO}$ - and OH-PBDEs has not been described to date (Haglund et al., 1997; Malmvärn et al., 2005; Valters et al., 2005). Methoxylated PBDEs have been previously identified in marine biota samples, such as algae, sponges, mussels, fish and mammals (Marsh et al., 2004; Malmvärn et al., 2005; Valters et al., 2005). MeO-PBDE concentrations in wild marine animals are generally higher than parent PBDE concentrations (Teuten et al., 2005; Valters et al., 2005; Malmvärn et al., 
2005; Malmvärn et al., 2008). In the marine environment, MeO-PBDEs are reported to originate mainly from natural products, i.e., bioformation in sponges or algae (Marsh et al., 2004; Valters et al., 2005; Teuten et al., 2005), although the possibility of formation via methylation of their hydroxylated homologues has also been reported (Haglund et al., 1997; Marsh et al., 2004; Teuten et al., 2005; Valters et al., 2005; Kelly et al., 2008; Malmvärn et al., 2008). MeO-PBDEs could also be formed directly in sediment or in organisms via hydroxylation followed by methylation by microorganisms (Haglund et al., 1997). However, they have never been reported as originating directly from PBDE metabolism in laboratory experiments, and this route, if it does occur, is considered as minor (Marsh et al., 2004).

OH-PBDEs may originate from natural sources or from in vivo metabolism. They have been identified in marine organisms such as algae, mussels and fish (Marsh et al., 2004; Malmvärn et al., 2005), as well as in abiotic compartments such as rain, snow and water (Ueno et al., 2008). OH-PBDEs have occasionally been found at higher concentrations than MeO-PBDEs in marine algae, mussels and fish (Malmvarn et al., 2005; de la Torre et al., 2009). Their production could originate directly from the algae itself, from associated microfauna or microflora, or from other organisms such as cyanobacteria (Unson et al., 1994; Malmvärn et al., 2005). More recently, it has been shown that MeO-PBDEs can also be demethoxylated to OH-PBDEs in vitro, at a faster rate than that of PBDE transformation to OH-PBDEs. This new finding could explain the high concentrations of OH-PBDEs sometimes reported in wildlife and increase the risk of biota exposure to OH-PBDEs (Wan et al., 2009). The occurrence of MeO- and $\mathrm{OH}-$ PBDEs at higher concentrations than those of PBDEs generally suggests that they are formed naturally (Wan et al., 2009). 
90 However, data on the unequivocal identification of OH-PBDEs in fish as a result of metabolism remains scarce. The formation of OH-PBDEs via metabolism is cytochrome P450 enzyme-mediated (Hakk and Letcher, 2003). As recently reviewed by Kelly et al. (2008), very few studies report the formation of OH-PBDEs from specific congeners in

fish under experimental conditions. Kierkegaard et al. (2001) reported the formation of 6 mono-hydroxylated metabolites of BDE-47 in pike (Esox lucius) after dietary exposure, with different profile distributions and levels in the various studied organs. Conversely, Burreau et al. (2000) reported no formation of hydrophilic metabolites in pike (Esox lucius) after dietary exposure to $\left[{ }^{14} \mathrm{C}\right]-\mathrm{BDE}-47$ using whole-body autoradiography rather than GC-MS. Similarly, OH-PBDE metabolites were not detected in the blood serum of juvenile carp (Cyprinus carpio) exposed to spiked food (Stapleton et al., 2004), or in Chinook salmon microsomes (Onchorhynchus tshawytscha) after exposure to BDE-99 (Browne et al., 2009). However, OH-PBDEs are likely to accumulate in organisms due to their high $\log \mathrm{K}_{\mathrm{ow}}$, in the $4.5-10.7$ range (Kelly et al., 2008).

Other studies have reported the identification of OH-PBDEs in fish collected in the field, although their natural origin or formation due to metabolism could not be demonstrated unequivocally. It has been shown that identified OH-PBDEs may be formed, for example, by oxidative processes in effluent discharged from wastewater and sewage treatment plants, then further accumulated in fish (Valters et al., 2005). More recently, de la Torre et al. (2009) reported the identification of both MeO- and OHPBDEs in the plasma of fish from Lake Ontario, with high concentrations of $\mathrm{OH}-$ PBDEs, some of which could possibly originate from fish metabolism. 
113 Although it remains difficult to firmly identify the origin of OH-PBDEs in environmental samples, this hurdle can be overcome by studying their occurrence in fish exposed to artificially-contaminated food, in controlled conditions.

The results presented in this paper are part of a larger project on the fate and effects of selected organic contaminants (PCBs, PBDEs, PAHs) in juvenile sole (Solea solea L.) exposed to food artificially contaminated with PBDEs in experimental conditions. The study aimed to identify the in vivo transformation products of selected PBDEs in sole and determine their accumulation and elimination kinetics. Results relating to PBDEs and their debrominated metabolites in fish tissues are presented in a separate paper (Munschy et al., 2011). The present paper focuses on the study of MeO-PBDEs and OH- PBDEs in fish exposed to PBDEs, and results were compared with those obtained in control fish followed up simultaneously. As OH-PBDEs have a higher affinity for plasma proteins than for lipids (Gebbink et al., 2008), fish blood plasma was examined for the presence of $\mathrm{OH}-$ congeners. For analytical reasons, fish blood was also examined for $\mathrm{MeO}$ - congeners.

\section{Materials and Methods}

The experimental design and analytical procedures used for the experiment are described in detail in the first part of this study and references therein, including the treatment of wastes and water decontamination design (Munschy et al., 2011). The main aspects are briefly summarized below.

\subsection{Experiment}


Juvenile sole (Solea solea L.) obtained from a commercial hatchery (Solea BV, Ijmuiden, Netherlands) were maintained in separate $4 \mathrm{~m}^{2}$ (circa $400 \mathrm{~L}$ ) tanks receiving a continuous flow of sea water from the roadstead of Brest (Brittany, France), maintained at $12 \mathrm{~h} \mathrm{light} / 12 \mathrm{~h}$ dark photoperiods and at a constant temperature $\left(19 \pm 1{ }^{\circ} \mathrm{C}\right)$. The fish were allowed to acclimatize to experimental conditions for 5 weeks before the experiment began.

Spiked food was prepared by slowly adding $160 \mathrm{ml}$ of a solution of known-amounts of PBDE congeners (i.e., BDE-28, BDE-47, BDE-99, BDE-100, BDE-153, BDE-209) diluted in iso-octane to $4 \mathrm{~kg}$ of commercial food (DAN-EX 1562, pellet size $2 \mathrm{~mm}$, produced by Dana Feed, Denmark) using an automatic mixer. Spiked food was stored in amber containers in a dark and cool place during its use (circa 1.5 month). Contamination levels of the individual congeners were systematically checked on each of the three food batches used, and followed over the duration of the batch use. Concentrations of individual congeners were between $82 \pm 5 \mathrm{ng} \mathrm{g}^{-1}$ wet weight (ww) and $93 \pm 6 \mathrm{ng} \mathrm{g}^{-1} \mathrm{ww}$ for BDE-28, BDE-47, BDE-99 and BDE-100, and $181 \pm 16 \% \mathrm{ng}$ $\mathrm{g}^{-1}$ ww and $184 \pm 23 \mathrm{ng} \mathrm{g}^{-1}$ ww for BDE-153 and BDE-209, respectively (mean value \pm standard deviation $-\mathrm{SD}, \mathrm{n}=20$ batch replicates). Non-spiked food was also analysed for PBDE levels, and concentrations were between $<0.005 \mathrm{ng} \mathrm{g}^{-1} \mathrm{ww}$ and $0.39 \mathrm{ng} \mathrm{g}^{-1} \mathrm{ww}$ depending on the congener.

The fish $(\mathrm{n}=470)$ were exposed to artificially-contaminated food for 84 days followed by non-spiked food for 149 days. In order to check if the addition of solvent to food had any effect on the study parameters, two types of control fish (mean initial weight $=17.4$ g) were considered and separated in between two tanks: one tank corresponded to fish $(n=474)$ fed commercial food, and one tank to fish $(n=492)$ fed commercial food to 
which solvent (iso-octane) was added. Individual daily food rations were adjusted according to fish size and biomass in each tank throughout the experiment, and were $0.8 \%$ of fish body weight / day, on average.

Fish were sampled from the tank receiving contaminated food on days $0,8,14,28,56$, 84 (contamination period), and on days 91, 98, 112, 140, 168 and 233 (depuration period). Fish from the control tanks were sampled on days $0,14,84,91,140,168$ and 233. Fish were systematically sampled after a 24-hour period of fasting. Fish size and weight were recorded individually, immediately after anaesthesia with phenoxy-ethanol. Fish blood was collected from cardiac muscle, placed in tubes containing the anticoagulant heparin and immediately centrifugated at high speed (12 $000 \mathrm{rpm})$ for 5 minutes. The resulting plasma was stored at $-80^{\circ} \mathrm{C}$ pending further processing. Samples were made from pooled individuals of $\mathrm{n}=8$ to 20 fish, depending on fish size, and replicate pools ( $\mathrm{n}=2$ to 3 ) were generally processed. Animal care guidelines were applied throughout the experiment by experienced staff.

\subsection{Standards and reagents}

The solvents (DCM, cyclohexane, acetone, ether, methanol, n-hexane, toluene) used for analyses were of trace analysis grade and supplied by SDS (France). Polystyrene gel beads Bio-Bead S-X3 (200-400 Mesh) were supplied by Bio-Rad Laboratories Inc. (USA). Silica gel (100-200 Mesh) and aluminium oxide (90 standardized) were supplied respectively by Sigma Aldrich (Germany) and Merck (Germany). PBDEs used to prepare spiked food were purchased from AccuStandard ${ }^{\circledR}$ Inc. (New Haven, CT, USA) and their purity was above $98 \%$. Standard solutions used for calibration, recovery surrogates added before extraction and internal standard solution added before injection, 
were obtained from Wellington Laboratories Inc. (Ontario, Canada), Cambridge Isotope Laboratories Inc. (Andover, MA, USA) or AccuStandard ${ }^{\circledR}$ Inc. (New Haven, CT, USA).

\subsection{Sample preparation}

Fish plasma samples were analysed for PBDEs, MeO-PBDEs and OH-PBDEs using a protocol adapted from Berger et al. (2004). Plasma samples, mixed with acidified sodium sulphate ( $1 \%$ concentrated sulphuric acid $96 \%)$, were spiked with recovery standards (BDE-139, and the labelled ${ }^{13} \mathrm{C}-6-\mathrm{MeO}-\mathrm{BDE}-47,{ }^{13} \mathrm{C}-6$ '-MeO-BDE-100, ${ }^{13} \mathrm{C}-$ 6-OH-BDE-47 and ${ }^{13} \mathrm{C}-6$ '-OH-BDE-100), extracted using cyclohexane:acetone $3: 1 \mathrm{v} / \mathrm{v}$, purified by Gel Permeation Chromatography and fractionated on Florisil columns (1.5 g de-activated at $0.5 \% \mathrm{w} / \mathrm{w}$ water, $60-100$ Mesh particles) eluted with sequential mixes of $11 \mathrm{ml}$ of $n$-hexane:DCM (3:1 v/v), $6 \mathrm{ml}$ of $n$-hexane:acetone $(85: 15 \mathrm{v} / \mathrm{v})$, and $10 \mathrm{ml}$ of DCM:methanol (88:12, v/v). The neutral fraction containing PBDEs and MeO-PBDEs was eluted first. The second and the third fractions containing $\mathrm{OH}$ - congeners, including the two OH-BDE recovery standards, were combined and derivatised overnight in the fridge using diazomethane. Diazomethane was prepared using Diazald (Sigma Chemical Co) in ether for each sample batch and used on the day of preparation. PBDE, MeOand $\mathrm{OH}$ - fractions were subsequently purified on acidified (minimum of $22 \%$ sulphuric acid) silica column (100-200 Mesh) eluted with 40ml of 15\% DCM in hexane.

Lipid content (determined as solvent-extractable organic matter) was determined in plasma samples using a gravimetric method and ranged between $0.7 \%$ and $3 \% \mathrm{ww}$, i.e., very similar to the levels found in various species of pelagic fish collected in the Detroit river in Canada (Li et al., 2003). These levels were fairly low, as the fish analysed in our study were fed with food containing a higher lipid content (13\%) than usually found in 
the wild. As lipid percentages do not generally correlate with MeO- and OH-PBDE concentrations, no lipid correction was applied and concentrations were expressed on a wet weight basis (Valters et al., 2005).

\subsection{Instrumental analysis}

Fish plasma samples were analysed for PBDEs using a Gas Chromatograph (Agilent $6890)$ coupled to a Mass Spectrometer (5973N) operated in negative chemical ionisation mode as described in the first part of this study (Munschy et al., 2011). Both the MeO- and $\mathrm{OH}$ - fractions were analysed using High Resolution Gas Chromatography - High Resolution Mass Spectrometry with an AutoSpec Ultima (Micromass, Manchester, UK) operated in electronic impact ionisation mode at a minimum resolution of 10000 in the selected ion monitoring mode. The source was maintained at $280^{\circ} \mathrm{C}$ and the filament was operated at a trap current of $650 \mu \mathrm{A}$ and an electron voltage of $35 \mathrm{eV}$, although the latter value was optimised for each filament. The MS was calibrated using perfluorokerosene and resolution was checked after each sample injection throughout the whole sequence of runs. The GC was equipped with a DB-1 (J\&W Scientific, USA) capillary column (30 m x $0.25 \mathrm{~mm}$ x $0.1 \mu \mathrm{m})$, which allowed good separation of $\mathrm{MeO}$ - derivatives within the 20 -minute runs. The column was programmed as follows: the initial oven temperature was $100^{\circ} \mathrm{C}$ held for 1 minute, ramped to $180^{\circ} \mathrm{C}$ at $40^{\circ} \mathrm{C} /$ minute with no hold time, ramped to $240^{\circ} \mathrm{C}$ at $15^{\circ} \mathrm{C} /$ minute with no hold time, ramped to $280^{\circ} \mathrm{C}$ at $4^{\circ} \mathrm{C} /$ minute with no hold time, then ramped to $320^{\circ} \mathrm{C}$ at $20^{\circ} \mathrm{C} /$ minute and held for 1 minute. Gas flow of Helium was $0.8 \mathrm{ml} /$ minute. This column was used for quantification, while a longer column (Rtx - 5MS, $60 \mathrm{~m} \mathrm{x}$ $0.25 \mathrm{~mm} \times 0.1 \mu \mathrm{m}$, Restek Corp., USA) was also used to confirm the identification of 
the compounds. The program used for the longer column was: $80^{\circ} \mathrm{C}$ ( 1 minute), to $250^{\circ} \mathrm{C}$ at $10^{\circ} \mathrm{C} /$ minute (held for 5 minutes), to $300^{\circ} \mathrm{C}$ at $3^{\circ} \mathrm{C} /$ minute (held for 15 minutes). Gas flow of $\mathrm{He}$ was $0.8 \mathrm{ml} /$ minute. Injections of $1 \mu \mathrm{l}$ of samples and standards were done in toluene in the splitless mode.

Identification of MeO- and $\mathrm{OH}-\mathrm{PBDEs}$ was achieved by comparing their retention times to those of authentic $\mathrm{MeO}$ - or derivatised $\mathrm{OH}$ - standards used as reference and by comparing their isotopic ratio with their theoretical ratio. The calibration standards (Wellington Laboratories, Canada) used to identify and quantify the MeO-PBDEs contained four native MeO-tetraBDEs (5-MeO-BDE-47, 6-MeO-BDE-47, 4'-MeOBDE-49, 2'-MeO-BDE-68), four native MeO-pentaBDEs (5'-MeO-BDE-99, 5'-MeOBDE-100, 4'-MeO-BDE-101, 4'-MeO-BDE-103), plus ${ }^{13}$ C-labelled 6-MeO-BDE-47 and ${ }^{13} \mathrm{C}$-labelled 6'-MeO-BDE-100 used as internal recovery standards, added at the beginning of the sample treatment. The native $\mathrm{OH}$ - congeners used for $\mathrm{OH}-\mathrm{PBDE}$ quantification were obtained from individual solutions (AccuStandard Inc., USA), i.e., the OH-triBDE 4'-OH-BDE-17, the OH-tetraBDEs 4-OH-BDE-42, 3-OH-BDE-47, 5OH-BDE-47, 6-OH-BDE-47, 4'-OH-BDE-49 and 2'-OH-BDE-68, the OH-pentaBDEs 6'-OH-BDE-85, 4'-OH-BDE-90 and 6'-OH-BDE-99. ${ }^{13} \mathrm{C}$ labelled 6-OH-BDE-47 and ${ }^{13} \mathrm{C}$ labelled 6'-OH-BDE-100 (Wellington Laboratories, Canada) were used as internal recovery standards after derivatisation.

MeO-PBDEs were quantified using the most abundant ions $[\mathrm{M}]^{+}: \mathrm{m} / \mathrm{z} 357.9028$ for MeO-Br2-BDEs, 435.8133 for MeO-Br3-BDEs, 515.7217 for MeO-Br4-BDEs, 593.6323 for MeO-Br5-BDEs, and 673.5408 for MeO-Br6-BDEs, and the corresponding $[\mathrm{M}+2]^{+}$identity confirmation ions reflecting the ${ }^{81} \mathrm{Br}$ and ${ }^{79} \mathrm{Br}$ isotopic contributions. 
256 Quantification of both $\mathrm{MeO}$ - and $\mathrm{OH}-\mathrm{PBDEs}$ was performed by isotopic dilution

257 method. Injection standards used to calculate the internal recovery standards were ${ }^{13} \mathrm{C}$ BDE-79 (for tribrominated to tetrabrominated analogues) and ${ }^{13} \mathrm{C}-\mathrm{BDE}-139$ (for pentabrominated to hexabrominated analogues). Whenever possible, individual $\mathrm{MeO}-$ and $\mathrm{OH}-\mathrm{PBDEs}$ were quantified in relation to their corresponding authentic standard.

MeO-PBDEs were quantified using the relative response factors (RRFs) obtained from a five-level calibration of the MeO-PBDEs mix. OH-PBDEs were quantified against derivatised standard solutions of OH-PBDEs. However, if authentic standards were unavailable, certain $\mathrm{OH}-\mathrm{PBDEs}$ were directly quantified in relation to their $\mathrm{MeO}-$ analogues rather than to derivatised $\mathrm{OH}-\mathrm{PBDE}$ (i.e., 4'-OH-BDE-101 and 4'-OHBDE-103).

\subsection{Quality assurance/quality control}

The entire analytical procedure was performed in clean laboratories maintained under positive atmospheric pressure and supplied with high-purity filtered air. Quality Assurance / Quality Control procedures were included for each batch of eight to ten samples. Blank samples were analysed using the same protocol as for samples and blanks were generally found to be free of any contamination by the targeted analytes. Method Detection Limits -MDLs-, calculated with the instrumental limit of detection, the mass of sample extracted and the final volume injection, ranged from $0.12 \mathrm{pg} \mathrm{g}^{-1}$ ww to $0.52 \mathrm{pg} \mathrm{g}^{-1}$ ww depending on the congeners. The two congeners 2'-MeO-BDE-68 and 6-MeO-BDE-47 were nevertheless identified in some blanks (MeO- fraction), at 0.26-0.53 $\mathrm{pg} \mathrm{g}^{-1}$ ww and 0.37-0.48 $\mathrm{pg} \mathrm{g}^{-1} \mathrm{ww}$, respectively, i.e., at levels 10 times to several orders of magnitude lower than the levels determined in samples. 
280 Recovery rates for individual internal standards ${ }^{13} \mathrm{C}$ - labelled 6-MeO-BDE-47 and 6'-

MeO-BDE-100 were $84 \pm 7 \%$ (SD) and $98 \pm 16 \%$, respectively $(n=33)$ for the MeOfraction, and $84 \pm 19 \%$ and $103 \pm 31 \%(\mathrm{n}=26)$ for ${ }^{13} \mathrm{C}$ labelled 6-OH-BDE-47 and 6'OH-BDE-100, respectively. Recovery rates for individual MeO-PBDEs and OH-PBDEs were evaluated on replicate plasma samples $(n=5)$ obtained from a control fish pooled sample spiked with a mix of the standard solution congeners. Replicates of non-spiked samples were also analysed and results were used to correct the recoveries of added congeners, whenever necessary. Mean recovery rates $(n=5)$ were between $99 \pm 8 \%$ (SD) and $102 \pm 11 \%$ for MeO-BDEs, and between $95 \pm 3 \%$ and $99 \pm 16 \%$ for targeted OH-PBDEs.

\section{Results and Discussion}

\subsection{Fish health and growth parameters}

Fish health and growth parameters were presented in the first part of this study (Munschy et al., 2011). Briefly, fish growth, liver somatic index and condition index showed no significant difference $(\mathrm{p}<0.05)$ in fish exposed to PBDE contaminated food and control fish. Mortality was low $(<2 \%)$ and was similar between both categories. As experimental parameters for health were good and similar for all conditions throughout the experiment, the results of PBDE biotransformation in fish could be compared all together.

\section{2. $\mathrm{MeO}-\mathrm{PBDES}$}

Among the eight specifically-targeted MeO-PBDEs, two congeners were identified by comparison with authentic standards in the fish plasma samples, i.e., 6-MeO-BDE-47 
and 2'-MeO-BDE-68. In addition, another pentabrominated $\mathrm{MeO}$ - congener was detected, although at much lower concentrations, but could not be identified using any of the authentic standards used in HRMS. The three congeners were quantified at levels between 116-270 $\mathrm{pg} \mathrm{g}^{-1} \mathrm{ww}, 58-158 \mathrm{pg} \mathrm{g}^{-1} \mathrm{ww}$ and 5-12 $\mathrm{pg} \mathrm{g}^{-1} \mathrm{ww}$, respectively (average values calculated on pooled fish replicates). Levels did not show any trends over time during the study period. The three congeners were also present in the plasma of the control fish and at the same concentration ranges as in fish exposed to contaminated food (Fig. 1), suggesting that the MeO-PBDEs detected in fish plasma did not result from fish exposure to PBDEs. Similar observations were made by Lebeuf et al. (2006) for 6-MeO-BDE-47 and 2'-MeO-BDE-68 in both control and PBDE-exposed Atlantic Tomcod. In addition, 6-MeO-BDE-47 and 2'-MeO-BDE-68 possess a MeOgroup in the ortho position, supporting the hypothesis that these compounds may originate from natural sources rather than PBDE metabolism (Malmvärn et al., 2005; Valters et al., 2005). Both compounds have already been identified in marine biota such as sponges, green algae, mussel and fish, including deep-sea species, (Kierkegaard et al., 2004; Marsh et al., 2004; Malmvärn et al., 2005; Covaci et al., 2008; de la Torre et al., 2009), as well as in marine mammals (Melcher et al., 2005; Weijs et al., 2009). Both congeners have also been unequivocally identified as being naturally produced using ${ }^{14} \mathrm{C}$ analysis of a True's beaked whale blubber sample (Teuten et al., 2005). Their presence has also been detected in the commercial food used in this experiment. In addition, fish were directly exposed to natural sea water throughout the experiment, as the tanks were supplied with a continuous flow of sea water. Therefore, accumulation from food and/or direct accumulation from water could have contributed to the occurrence of 6-MeO-BDE-47 and 2'-MeO-BDE-68 in fish studied during our 
experiment. These compounds have $\log \mathrm{K}_{\mathrm{ow}}$ values in the range of 6.3 to 7.2 (Kelly et al., 2008), enabling them to accumulate in tissues.

\section{3. $O H-P B D E s$}

Several OH-PBDEs were detected in fish plasma samples during this study. The following congeners were identified in relation to their retention time, isotopic ratio and derivatised authentic standards: 6-OH-BDE-47, 4'-OH-BDE-49, 4'-OH-BDE-101 and 4'-OH-BDE-103. Accumulation kinetics are shown in Fig. 2 for both control and exposed fish. The two major OH- congeners, 6-OH-BDE-47 and 4'-OH-BDE-49, were detected at concentrations ranging from $9 \mathrm{pg} \mathrm{g}^{-1} \mathrm{ww}$ to $95 \mathrm{pg} \mathrm{g}^{-1} \mathrm{ww}$ (in both control and exposed fish) and from $6 \mathrm{pg} \mathrm{g}^{-1} \mathrm{ww}$ to $30 \mathrm{pg} \mathrm{g}^{-1} \mathrm{ww}$ (exposed fish), respectively. The other two identified congeners, 4'-OH-BDE-101 and 4'-OH-BDE-103, were found to be in the 1.8-5.5 $\mathrm{pg} \mathrm{g}^{-1} \mathrm{ww}$ and 0.6-1.8 $\mathrm{pg} \mathrm{g}^{-1} \mathrm{ww}$ ranges, respectively, in exposed fish (Fig. 2). In addition, two OH-pentaBDEs were also detected, but could not be identified in relation to any of the standards employed. The latter congeners were detected at low levels, i.e., $0.5-1.8 \mathrm{pg} \mathrm{g}^{-1} \mathrm{ww}$, and in exposed fish only (results not shown).

While 6-OH-BDE-47 was detected in the plasma of control fish in a similar concentration range to that of exposed fish, 4'-OH-BDE-49 and 4'-OH-BDE-101 were found at much higher levels in exposed fish (Fig. 2). Congener 4'-OH-BDE-103 exhibited an intermediate behaviour.

Congeners 4'-OH-BDE-49 and 4'-OH-BDE-101 were below MDL (i.e., $<0.1-0.8 \mathrm{pg} \mathrm{g}^{-1}$ ww) in most control fish samples, and their levels remained significantly lower than those found in exposed fish (Fig. 2). This suggests that they probably originate from an 
in vivo $\mathrm{PBDE}$ transformation. Moreover, the $\mathrm{OH}$ - groups of both congeners are in the para position, which may indicate that they originate from PBDE metabolism (Marsh et al., 2004; Valters et al., 2005). Congener 4'-OH-BDE-49 may be derived from BDE-47 via CYP enzyme-mediated metabolism (Valters et al., 2005) or from BDE-49 hydroxylation (Marsh et al. 2004). BDE-49 was identified in both the tissues and blood of the same fish (Munschy et al., 2011, and below in paragraph 3.4). The formation of $4^{\prime}-\mathrm{OH}-\mathrm{BDE}-49\left(2,2^{\prime}, 4,5^{\prime}\right)$ from BDE-47 $\left(2,2^{\prime}, 4,4^{\prime}\right)$ is due to a 1,2 shift in the parabromine atom during the formation of $\mathrm{OH}$-metabolites (Qiu et al., 2007). This process could also explain the formation of 4'-OH-BDE-101 (2, 2', 4,5, 5') from BDE-99 (2, 2',4, 4',5). To our knowledge, 4'-OH-BDE-101 has never previously been identified as a PBDE metabolite in fish. The two other unknown pentabrominated $\mathrm{OH}$ - congeners are also thought to be of metabolic origin, as they were not identified in the control fish (i.e., below LOD). However, we were unable to ascertain the position of their $\mathrm{OH}-$ groups.

Both hydroxylated congeners accumulated in a linear manner during the 84-day fish exposure to food (Fig. 2). Rates of formation assessed using the linear relationship were $0.202 \mathrm{pg} \mathrm{g}^{-1}$ day $^{-1}$ and $0.046 \mathrm{pg} \mathrm{g}^{-1}$ day $^{-1}$ for 4'-OH-BDE-49 and 4'-OH-BDE-101, respectively. Interestingly, this increase in concentrations was followed by a rapid drop once exposure to contaminated food ceased, before reaching higher levels after the first month of depuration. These results would suggest a two-step formation of hydroxylated metabolites in blood, with metabolites initially formed from "fresh" contaminants brought through diet, and metabolites which may be formed subsequently from contaminants stored in tissues and remobilised via blood during the depuration period. Conversely, 6-OH-BDE-47 was detected at similar levels in both exposed fish and 
control fish (Fig. 2), ruling out the possibility of its main origin being metabolic transformation of PBDEs in sole exposed to PBDEs. Data from the literature reports that the presence of this congener in aquatic biota has been attributed to both natural and metabolic sources. 6-OH-BDE-47 has frequently been reported in aquatic biota at high levels, i.e., in red algae and salmon blood (Salmo salar) from the Baltic, in various fish species from the Detroit River and in marine sponges and ascidians (Marsh et al., 2004; Malmvärn et al., 2005; Valters et al., 2005). In addition, this congener has been reported as originating from various metabolic routes: it was one of the metabolites identified in the plasma and faeces of rodents exposed to PBDEs (Malmberg et al., 2005; Marsh et al., 2006), and the main congener detected in rain and snow from Ontario, Canada, where its origin from wastewater and sewage treatment plants could be partly due to human and animal metabolites (Ueno et al., 2008). Congener 6-OH-BDE-47 could also theoretically be formed from direct hydroxylation of BDE-47 (Marsh et al., 2004), although in our experiment, 6-OH-BDE-47 was found in similar levels in control fish and exposed fish, ruling out this process as its main origin. As presented above in paragraph 3.2, the $\mathrm{MeO}$ - analogue of 6-OH-BDE-47, i.e., 6-MeO-BDE-47, was also identified in our samples; this methoxylated congener could possibly be formed by the methylation of 6-OH-BDE-47 (Haglund et al., 1997; Marsh et al., 2004; Teuten et al., 2005). However, 6-MeO-BDE-47 was present at higher levels than 6-OH-BDE-47, hence arguing in favour of an origin other than 6-OH-BDE-47 methylation. The lack of formation of MeO-PBDEs from OH-PBDEs has also recently been reported during fish microsome incubations (Wan et al., 2009). Conversely, the same study reported the formation of 6-OH-BDE-47 via demethoxylation of 6-MeO-BDE-47: this could partly explain the formation of 6-OH-BDE-47 in our samples. The ratio between the MeO- 
and the $\mathrm{OH}-\mathrm{PBDE}$ congeners determined in our samples (about 4:1) is closed to what was previously found in the wild in Baltic sea salmon blood (Marsh et al., 2004; Asplund et al., 1999). In addition, OH- substitution in the ortho position with bromine atoms in the 2,4- positions in the non-hydroxylated ring reinforces the hypothesis that the 6-OH-BDE-47 identified in this study was of natural origin rather than a result of PBDE metabolism (Malmberg et al., 2005; Malmvärn et al., 2005).

Congener 4'-OH-BDE-103 was identified at similar levels in both exposed and control fish (Fig.2), although its levels were slightly higher in exposed fish. However, concentrations were very low and are hence to be judged with caution. To our knowledge, 4'-OH-BDE-103 has never previously been reported. Its molecular structure suggests that it may originate from BDE-100 hydroxylation. However, the likelihood of it originating from direct PBDE metabolism in our experiment is small, as this congener was also identified in the control fish. On the other hand, its $\mathrm{OH}$ - substitution in the para position is characteristic of metabolism rather than of natural origin. The presence of this compound in control fish at levels close to those found in exposed fish is still not fully understood and should be further examined.

Para- and meta- $\mathrm{OH}-$ metabolites, such as those found in fish plasma, are reported to be the most potent in terms of thyroxine-like activity and/or oestrogen-like activities (Qiu et al., 2007; Hamers et al., 2008). Their concentrations in the plasma of exposed fish were very low, i.e., in the $\mathrm{pg} \mathrm{g}^{-1} \mathrm{ww}$ range, which is far below the levels reported as producing in vitro effects (Meerts et al., 2000; 2001; Hamers et al., 2008). However, several studies in the wild have shown that OH-PBDEs may be present at high levels, and that $\mathrm{MeO}$ - congeners, which are sometimes present at high levels too, may also represent a source of OH-PBDEs (Wan et al., 2009). In addition to this, fish may be 
exposed to other hydroxylated organohalogens in the wild, which would lead to combined/additive effects, hence enhancing fish exposure to endocrine system function disrupters (Brouwer et al., 1998; Li et al., 2003; Hamers et al., 2008).

\subsection{OH-PBDEs to PBDEs ratio}

In order to calculate the ratio of PBDE congeners versus their metabolites in blood plasma, PBDEs were also quantified in blood plasma. All congeners to which fish were exposed through diet (i.e., BDE-28, BDE-47, BDE-99, BDE-100, BDE-153, BDE-209) were identified in blood, as well as some debrominated congeners such as BDE-49 and an unknown pentabrominated congener. These debrominated congeners have been also identified in fish tissues, and are more than likely the result of PBDE metabolism in fish (Munschy et al., 2011). Maximum concentrations in blood were in the 1.3-13.3 $\mathrm{ng} \mathrm{g}^{-1}$ ww range depending on the congener; these levels were in the same range as those estimated in the whole body, except for BDE-209, which showed higher maximum levels in blood. Interestingly, higher-brominated congener concentrations were higher in plasma than in the whole fish body during the first weeks of exposure; concentrations were subsequently similar in fish tissues. An example of this is illustrated in Fig. 3 for BDE-153. This observation indicates an initial faster rate of blood contamination after exposure through diet, followed by a subsequent transport of contaminants throughout the body via the blood. Conversely, as shown in Fig. 3, concentrations determined in plasma exhibited higher variations between pooled samples than those determined in the whole fish body. This could be explained by the dynamic properties of this circulating media.

Considering that both BDE-47 and BDE-49 were metabolised into 4'-OH-BDE-49, we 
calculated the ratio 4'-OH-BDE-49 / (BDE-47 + BDE-49), which was found to be between $0.11 \%$ and $0.51 \%$. This ratio did not show any trends over time during the study period (Fig. 4). In the same manner, based on the fact that BDE-99 was metabolised into 4'-OH-BDE-101, we calculated the ratio 4'-OH-BDE-101 / BDE-99.

This ratio was found to be between $0.07 \%$ and $4.2 \%$, and showed a linear increase during the depuration period (Fig. 4). This would tend to suggest that the transformation of BDE-99 into 4'-OH-BDE-101 was a continuous process during the whole experiment.

The ratios calculated in this study are consistent with data reported previously in the literature for fish or other marine species in the wild and show that OH-PBDEs do not represent major metabolic residues in fish exposed to PBDEs (Valters et al., 2005; Kelly et al., 2008).

\section{Conclusions}

This study highlighted the in vivo accumulation of OH-PBDEs in the plasma of sole exposed to food artificially contaminated with PBDEs. MeO-PBDEs were also found to accumulate in fish plasma, but were not found to originate from PBDE transformation. As expected from previously-published results, trends observed here for MeO-PBDEs suggest they are most likely of natural origin, i.e., originating from non-metabolic sources. On the other hand, we demonstrated that several OH-PBDEs were derived from PBDE metabolism in fish. The main identified hydroxylated metabolites were 4'OH-BDE-49 and 4'-OH-BDE-101. In addition, two unknown OH-pentaBDEs were identified as a result of PBDE metabolism in fish. OH-PBDEs accumulated in fish plasma during the exposure period and were still present at similar levels five months after exposure to contaminated food has ceased, suggesting a longer depuration rate 
473 than for the parent congeners. The detected hydroxylated congeners were present in fish 474 plasma at low levels, hence demonstrating that they are not a major route of PBDE 475 degradation in the study species in comparison to debrominated metabolites.

476 


\section{Acknowledgments}

477 This research was funded by the "Agence Nationale pour la Recherche" in the

478 framework of the "Vulnérabilité Milieux et Climat" project (ANR-06-PVULN-013).

479 The authors would like to thank Vincent Buchet (Ifremer Laboratory of Adaptation,

480 Reproduction, Nutrition) and his technical staff for their assistance in experimental

481 work and fish maintenance. This study was conducted under the approval of the Animal

482 Care Committee of France under the official licence of Vincent Buchet (972-1). Colin

483 Darling from Environment Canada is gratefully acknowledged for his valuable guidance

484 in the development of PBDE metabolite analysis in fish plasma. C. Munschy wishes to

485 thank the Ministry of Foreign Affairs under the EGIDE program for the grant received

486 for collaboration with the Aquatic Ecosystem Protection Research Division,

487 Environment Canada. Laura Valentine from "English Assistance for Industry" is

488 acknowledged for the English corrections made to the manuscript. 


\section{References}

Asplund, L., Athaniasou, M., Sjodin, A., Bergman, A., Borjeson, H., 1999. Organohalogen substances in muscle, egg and blood from healthy Baltic salmon (Salmo salar) and Baltic salmon that produced offspring with the M74 syndrome. Ambio 28, 67-76.

Berger, U., Herzke, D., Sandanger, T.M., 2004. Two trace analytical methods for determination of hydroxylated PCBs and other halogenated phenolic compounds in eggs from Norwegian birds of prey. Analytical Chemistry 76, 441-452.

Brouwer, A., Morse, D.C., Lans, M.C., Schuur, A.G., Murk, A.J., Klasson Wehler, E., Bergman, Ä., Visser, T.J., 1998. Interactions of persistent environmental organohalogens with the thyroid hormone system: mechanisms and possible consequences for animal and human health. Toxicology and Industrial Health 14, 5984.

Browne, E.P., Stapleton, H.M., Kelly, S.M., Tilton, S.C., Gallagher, E.P., 2009. In vitro hepatic metabolism of 2,2',4,4',5-pentabromodiphenyl ether (BDE-99) in Chinook salmon (Onchorhynchus tshawytscha). Aquatic Toxicology 92, 281-287.

Burreau, S., Broman, D., Orn, U., 2000. Tissue distribution of 2,2’24,4’tetrabromo $\left[{ }^{14} \mathrm{C}\right]$ diphenyl ether $\left(\left[{ }^{14} \mathrm{C}\right]-\mathrm{PBDE}-47\right)$ in pike (Esox lucius) after dietary exposure - a time series study using whole body autoradiography. Chemosphere 40, $977-985$.

Covaci , A., Losada, S., Roosens, L., Vetter, W., Santos, F.J., Neels, H., Storelli, A., Storelli, M.M., 2008. Anthropogenic and naturally occurring organobrominated 
compounds in two deep-sea fish species from the Mediterranean Sea. Environmental Science and Technology, 42, 8654-8660.

Darnerud, P-O., Eriksen, G.S., Jóhannesson, T., Larsen, P.B., Viluksela, M., 2001. Polybrominated Diphenyl Ethers: Occurrence, Dietary Exposure, and Toxicology. Environmental Health Perspectives 109 (suppl. 1), 49-68.

de la Torre, A., Pacepavicius, G., Martinez, M.A., Darling, C., Muir, D., Alaee, M., 2009. Methoxylated and hydroxylated polybrominated diphenyl ethers in brown bullhead (Ameiurus nebulosus) plasma from Lake Ontario. Organohalogen Compounds, 71, 2120-2123.

de Wit, C.A., 2002. An overview of brominated flame retardants in the environment. Chemosphere 46, 583-624.

Gebbink, W.A., Sonne, C., Dietz, R., Kierkegaard, M., Born, E.W., Muir, D.C.G., Letcher, R.J., 2008. Target tissue selectivity and burdens of diverse classes of brominated and chlorinated contaminants in polar bears (Ursus maritimus) from East Greenland. Environmental Science and Technology 42, 752-759.

Haglund, P.S., Zook, D.R., Buser, H.-R., Hu, J., 1997. Identification and quantification of polybrominated diphenyl ethers and methoxy-polybrominated diphenyl ethers in Baltic biota. Environmental Science and Technology 31, 3281-3287.

Hakk, H., Letcher, R.J., 2003. Metabolism in the toxicokinetics and fate of brominated flame retardants - a review. Environment International 29, 801-828.

Hamers, T., Kamstra, J.H., Sonneveld, E., Murk, A.J., Visser, T.J., Van Velzen, M.J.M., Brouwer, A., Bergman, Ä., 2008. Biotransformation of brominated flame retardants into potentially endocrine-disrupting metabolites, with special attention to 2,2',4,4'- 
tetrabromodiphenyl ether (BDE-47). Molecular Nutrition and Food Research 52, 284-298.

Hites, R.A., 2004. Polybrominated diphenyl ethers in the environment and in people: a meta-analysis of concentrations. Environmental Science and Technology 38, 945956.

Kelly, B.C., Ikonomou, M.G., Blair, J.D., Gobas, F.A.P.C., 2008. Hydroxylated and methoxylated polybrominated diphenyl ethers in a Canadian Arctic marine food web. Environmental Science and Technology 42, 7069-7077.

Kierkegaard, A., Burreau, S., Marsh, G., Klasson-Wehler, E., de Wit, C., Asplund, L., 2001. Matabolism and distribution of 2,2',4,4'-tetrabromo $\left[{ }^{14} \mathrm{C}\right]$ diphenyl ether in pike (Esox lucius) after dietary exposure. Organohalogen Compounds, 52, 58-61.

Kierkegaard, A., Bignert, A., Sellström, U., Olsson, M., Asplund, L., Jansson, B., de Wit, C.A., 2004. Polybrominated diphenyl ethers (PBDEs) and their methoxylated derivatives in pike from Swedish waters with emphasis on temporal trends, 19672000. Environmental Pollution 130, 187-198.

Law, R.L.J., Alaee, M., Allchin, C.R., Boon, J.P., Lebeuf, M., Lepom, P., Stern, G.A., 2003. Levels and trends of and other brominated flame retardants in wildlife. Environment International 29, 757-770.

Law, R.LJ., Allchin, C.R., de Boer, J., Covaci, A., Herzke, D., Lepom, P., Morris, S., Tronczynski, J., de Wit, C., 2006. Levels and Trends of Brominated Flame Retardants in the European Environment. Chemosphere 64, 187-208. 
Lebeuf, M., Couillard, C.M., Légaré, B., Trottier, S., 2006. Effects of DeBDE and PCB126 on hepatic concentrations of PBDEs and methoxy-PBDEs in Atlantic Tomcod. Environmental Science and Technology 40, 3211-3216.

Legler, J., 2008. New insights into the endocrine disrupting effects of brominated flame retardants. Chemosphere 73, 216-222.

Li, H., Drouillard, K.G., Bennett, E., Haffner, G.D., Letcher, R.J., 2003. Plasmaassociated halogenated phenolic contaminants in benthic and pelagic fish species from the Detroit River. Environmental Science and Technology 37, 832-839.

Malmberg, T., Athanasiadou, M., Marsh, G., Brandt, I., Bergman, Ä., 2005. Identification of hydroxylated polybrominated diphenyl ether metabolites in blood plasma from polybrominated diphenyl ether exposed rats. Environmental Science and Technology 39, 5342-5348.

Malmvärn, A., Marsh, G., Kautsky, L., Athanasiadou, M., Bergman, A., Asplund, L., 2005. Hydroxylated and methoxylated brominated diphenyl ethers in the red algae Ceramium tenuicorne and blue mussels from the Baltic Sea. Environmental Science and Technology 39, 2990-2997.

Malmvärn, A., Zebühr, Y., Kautsky, L., Bergman, A., Asplund, L., 2008. Hydroxylated and methoxylated polybrominated diphenyl ethers and polybrominated dibenzo-pdioxins in red alga and cyanobacteria living in the Baltic Sea. Chemosphere 72, 910916.

Marsh, G., Athanasiadou, M., Bergman, A., Asplund, L., 2004. Identification of hydroxylated and methoxylated polybrominated diphenyl ethers in Baltic Sea salmon (Salmo salar) blood. Environmental Science and Technology 38, 1, 10-18. 
Marsh, G., Athanasiadou, M., Athanassiadis, I., Sandholm, A, 2006. Identification of hydroxylated metabolites in 2,2',4,4'-tetrabromodiphenyl ether exposed rats. Chemosphere 63, 690-697.

Meerts, I.A.T.M., van Zanden, JJ., Luijks E.A.C., Van Leeuwen-Bol, I., Marsh, G., Jakobsson, E., Bergman, A, Brouwer, A. 2000. Potent competitive interactions of some brominated flame retardants and related compounds with human transthyretin in vitro. Toxicological Sciences 56, 95-104.

Meerts, I.A.T.M., Letcher, R.J., Hoving, S., Marsh, G., Bergman, Ä., Lemmen, J.G., van der Burg, B., Brouwer, A., 2001. In vitro estrogenicity of polybrominated diphenyl ethers, hydroxylated PBDEs, and polybrominated bisphenol A compounds. Environmental Health Perspectives 109, 399-407.

Melcher, J., Olbrich, D., Marsh, G., Nikiforov, V., Gaus, C., Gaul, S., Vetter, W., 2005. Tetra- and tribromophenoxyanisoles in marine samples from Oceania. Environmental Science and Technology 39, 7784-7789.

Munschy, C., Héas-Moisan, K., Tixier, C., Olivier, N., Gastineau, O., Le Bayon, N., Buchet, V., 2011. Dietary exposure of juvenile common sole (Solea solea L.) to polybrominated diphenyl ethers (PBDEs): Part 1. Bioaccumulation and elimination kinetics of individual congeners and their debrominated metabolites. Environmental Pollution 159, 229-237.

Qiu, X., Mercado-Feliciano, M., Bigsby, R.M., Hites, R.A., 2007. Measurement of polybrominated diphenyl ethers and metabolites in mouse plasma after exposure to a commercial pentabromodiphenyl ether mixture. Environmental Health Perspectives 115, 1052-1058. 
Ross, P.S., Couillard, C.M., Ikonomou, M.G., Johannessen, S.C., Lebeuf, M., Macdonald, R.W., Tomy, G.T., 2009. Large and growing environmental reservoirs of Deca-BDE present an emerging health risk for fish and marine mammals. Marine Pollution Bulletin 58, 7-10.

Shaw, S.D., Kannan, K., 2009. Polybrominated diphenyl ethers in marine ecosystems of the American continents : foresight from current knowledge. Reviews on Environmental Health 24, 157-229.

Stapleton, H.M., Letcher, R.J., Li, J., Baker, J.E., 2004. Dietary accumulation and metabolism of polybrominated diphenyl ethers by juvenile carp (Cyprinus carpio). Environmental Toxicology and Chemistry 23, 1939-1946.

Tanabe, S., Ramu, K., Isobe, T., Takahashi, S., 2008. Brominated flame retardants in the environment of Asia-Pacific: an overview of spatial and temporal trends. Journal of Environmental Monitoring 10, 188-197.

Teuten, E.L., Xu, L., Reddy, C.M., 2005. Two abundant bioaccumulated halogenated compounds are natural products. Science 307, 917-920.

Ueno, D., Darling, C., Alaee, M., Pacepavicius, G., Teixeira, C., Campbell, L., Letcher, R.J., Bergman, A., Marsh, G., Muir, D., 2008. Hydroxylated polybrominated diphenyl ethers (OH-PBDEs) in the abiotic environment : surface water and precipitation from Ontario, Canada. Environmental Science and Technology 42, $1657-1664$

Unson, M.D., Holland, N.D., Faulkner, D.J., 1994. A brominated secondary metabolite synthesized by the cyanobacterial symbiont of a marine sponge and accumulation of the crystalline metabolite in the sponge tissue. Ambio 119, 1-11. 
624 Valters, K., Li, H., Alaee, M., D’Sa, I., Marsh, G., Bergman, A., Letcher, R.J., 2005.

625 Polybrominated diphenyl ethers and hydroxylated and methoxylated brominated and

626 chlorinated analogues in the plasma of fish from the Detroit river. Environmental

$627 \quad$ Science and Technology 39, 5612-5619.

628 Wan, Y., Wiseman, S., Chang, H., Zhang, X., Jones, P.D., Hecker, M., Kannan, K.,

629 Tanabe, S., Hu, J., Lam, M.H.W., Giesy, J.P., 2009. Origin of hydroxylated

630 brominated diphenyl ethers: natural compounds or man-made flame retardants ?

631 Environmental Science and Technology 43, 7536-7542.

632

633

634

635

636

Weijs, L., Losada, S., Das, K., Roosens, L., Reijnders, P.J.H., Santos, J.F., Neels, H., Blust, R., Covaci, A., 2009. Biomagnification of naturally-produced methoxylated polybrominated diphenyl ethers (MeO-PBDEs) in harbour seals and harbour porpoises from the Southern North Sea. Environment International 35, 893-899. 
$636 \quad$ Figure legends

637 Figure 1

638 Concentrations ( $\mathrm{pg} \mathrm{g}^{-1} \mathrm{ww} \pm \mathrm{SD}$ ) of MeO-PBDEs in blood plasma of fish (pooled 639 samples) exposed to PBDEs through artificially-contaminated diet and in control fish. 640 Standard deviations of the mean obtained on replicate pooled samples are presented. 641 $642 \quad$ Figure 2

643 Concentrations ( $\mathrm{pg} \mathrm{g}^{-1} \mathrm{ww} \pm \mathrm{SD}$ ) of OH-PBDEs in blood plasma of fish (pooled 644 samples) exposed to PBDEs through artificially-contaminated diet and in control fish.. 645 Standard deviations of the mean obtained on replicate pooled samples are presented. 646 $647 \quad$ Figure 3

648 Concentrations ( $\mathrm{ng} \mathrm{g}^{-1} \mathrm{wW} \pm \mathrm{SD}$ ) of BDE-153 in blood plasma and whole body of fish 649 exposed to PBDEs through artificially-contaminated diet. Standard deviations of the 650 mean obtained on replicate pooled samples are presented.

651

652 Figure 4

653 Variation of ratios (\%) of OH-PBDEs to their PBDE precursors in blood plasma over 654 the experiment of fish exposed to PBDEs through artificially-contaminated diet. 
Figure 1
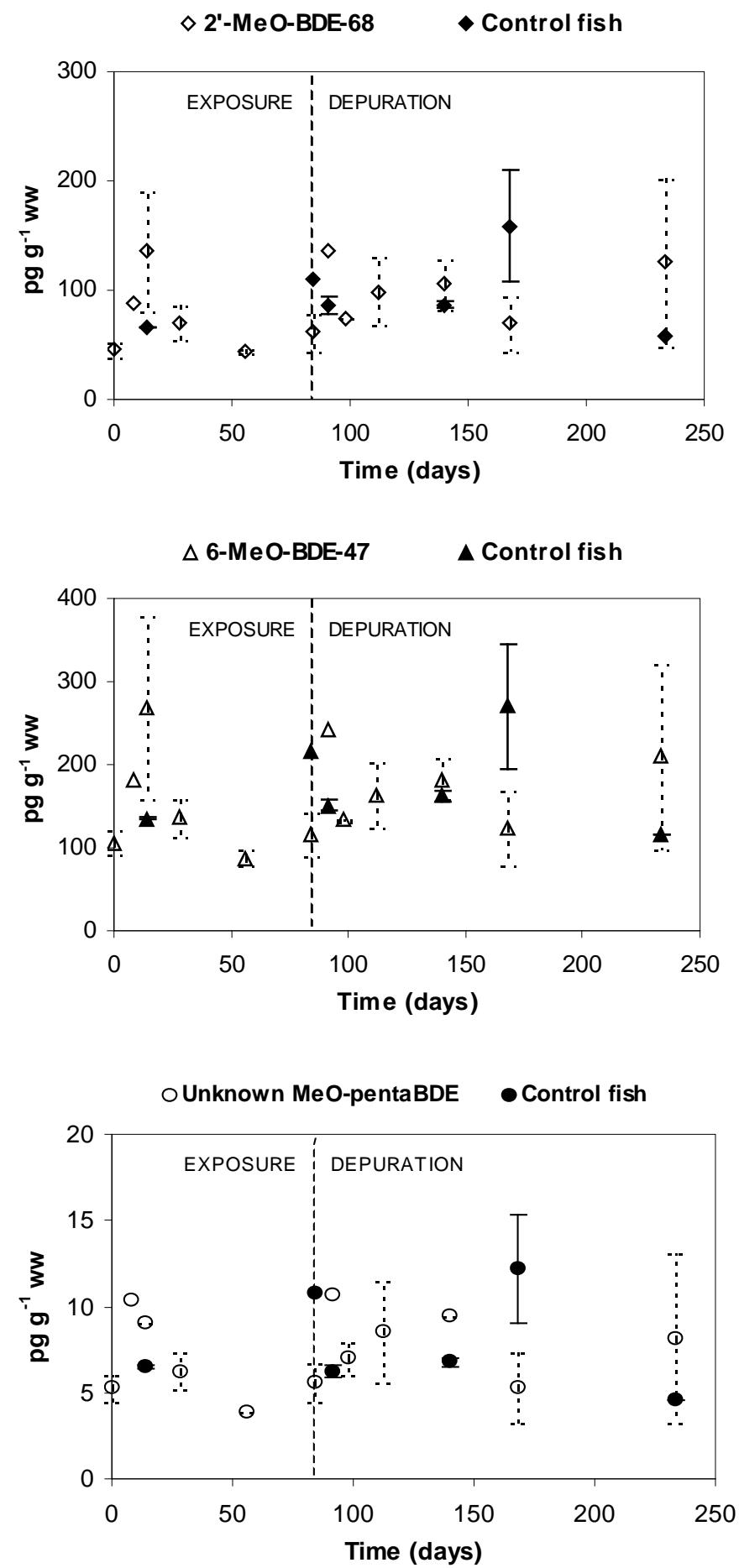
Figure 2
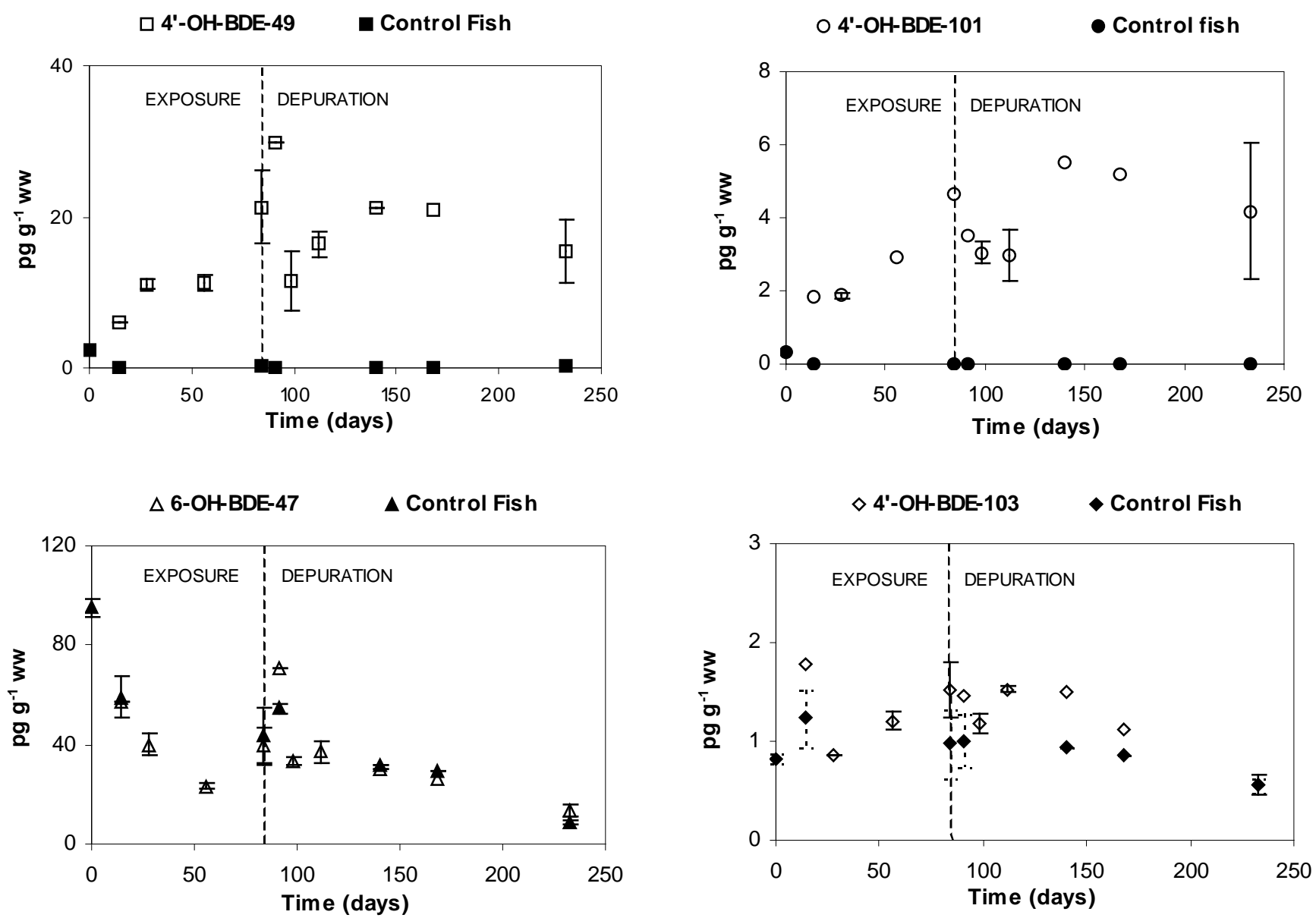
Figure 3

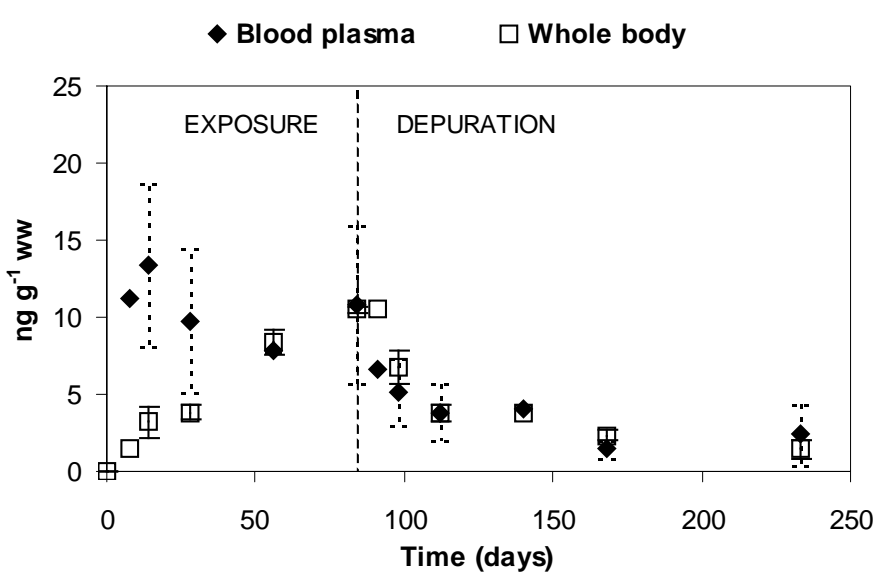


Figure 4

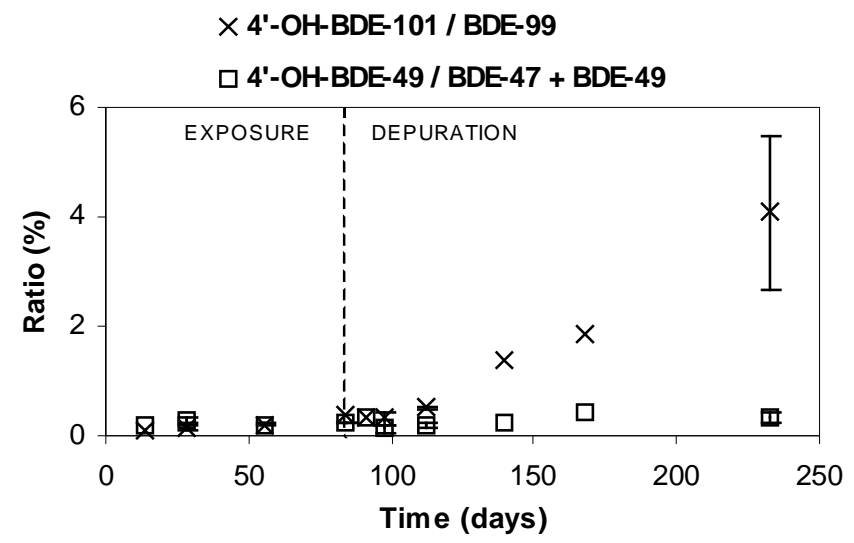

